\title{
Contemporary views on dementia as witchcraft in sub-Saharan Africa: a systematic literature review.
}

Brooke, J.M., Ojo, O.

\section{Abstract}

Aim: A systematic review to explore the impact of cultural beliefs of dementia as witchcraft in sub-Saharan Africa.

Background: The population of sub-Saharan Africa is aging, which increases the number of those at risk of dementia. Mental health and physical diseases that affect behaviour have often been associated with witchcraft. Accusations of witchcraft leave individuals vulnerable and at risk.

Method: A systematic review, which followed the Preferred Reporting for Systematic Reviews and Meta-Analyses (PRISMA) guidelines and completed a PRISMA checklist. CINHAL, PsychINFO, Web of Knowledge, PubMed and Science Direct databases were searched for relevant studies published from their inception to $31^{\text {st }}$ May 2019 by applying appropriate Medical Subject Headings. Data analysis adhered to Thomas and Harding's thematic synthesis.

Results: The review identified limited literature on this topic, with only five papers meeting the inclusion and exclusion criteria. Studies explored health provision, and knowledge and beliefs of dementia in Tanzania and South Africa. Three themes emerged: 1) poor knowledge of dementia, including the belief of dementia as witchcraft; 2) challenges of supporting a family member with dementia in the community; and 3) health seeking behaviours of and for people with dementia.

Conclusion: There remains a need for dementia awareness and education across subSaharan Africa communities, including faith and traditional healers, and healthcare professionals to support pluralistic healthcare provision. Nurses are the best-placed healthcare professionals to support these initiatives and the development and implementation of low-resource non-pharmacological interventions to support people with dementia and their families living in the community.

Relevance to clinical practice: Nurses working in sub-Saharan Africa and those caring for patients from sub-Saharan Africa can only provide person-centred care and support for a person with dementia and their family if they understand their cultural beliefs, one of which may include witchcraft. 


\section{What does this paper contribute to the wider global clinical community?}

- People in sub-Saharan Africa may hold incongruent beliefs of dementia, such as some accurate knowledge and the belief of dementia as witchcraft.

- Supporting a person with dementia in the community in sub-Saharan Africa is challenging due to isolation caused by the stigma of dementia as witchcraft.

- Health seeking behaviour in sub-Saharan Africa were pluralistic in nature, supporting underlying beliefs of dementia as witchcraft, whilst seeking modern care.

\section{INTRODUCTION}

The world's population is aging and the most rapidly aging population is in sub Saharan Africa, as it has been estimated that those over the age of 60 will increase from 46 million people in 2015 to 157 million people by 2050 (Aboderin \& Beard, 2014). The aging population increases those at risk of dementia. In 2015, an estimated 186,000 people were living with dementia in South Africa, which is predicted to increase to 275,000 by 2030 , of which 225,000 of those are expected to be women (World Alzheimer Report, 2016). The portion of older women with dementia is important, due to the low status of women across regions of sub Saharan Africa, it is older women who are overwhelmingly accused of witchcraft or being a witch (Krug et al., 2002; Samber, Avanger, \& Abanyam, 2004).

In sub Saharan Africa, many traditional spiritual beliefs and practices include witchcraft (Appiah, 1991). An absolute definition of witchcraft is difficult, as the concepts and beliefs vary across sub Saharan cultures (Crampton, 2013). An understanding of witchcraft would need to include both the act of witchcraft "harmful actions carried out by persons presumed to have access to supernatural powers" (Ashforth, 1998: 64) and the impact of witchcraft the misfortune and loss, which has been inflicted onto a person (Simmons, 1980). However, witchcraft is a construct of modernity that addresses tensions within society, and provides an explanation for events, which have no logical explanation, such as illnesses, sudden death, misfortune, bad luck, and crop failure (Saunders, 2003).

Elderly women are one of the most vulnerable members of society in sub-Saharan Africa, and at risk of being accused of witchcraft or being a witch, or are perceived to have outlived their usefulness (Bastian, 2002). Community accusations of witchcraft correspond with direct or indirect harm to others, such as road accidents, unemployment, infertility, and physical and mental health problems (Witchcraft and Human Rights Information Network [WHRIN], 2013). From this perspective, a witch has caused harm in the physical realm by evolving a 
malevolent force from the spirit world, such as an ancestors' spirit (Ndamba-Bandzouzi et al., 2014).

An accusation of witchcraft or being a witch has many negative connotations, as those who hold these beliefs, also believe that it is acceptable to dehumanise a witch and act violently towards them (Mouton \& Southerland, 2017). Elderly women believed to be witches become socially and physically isolated, often abandoned by family members. These women face abuse through the lack of basic amenities, including food and healthcare, which ultimately leads to poor health and death (Atata, 2018). In some areas of sub Saharan Africa, 'witch camps' have become a place of refuge for many elderly women, where those who have been accused of witchcraft live in exile under harsh conditions but free from violence (Palmer, 2010).

The link between accusations of witchcraft of people with behaviours that are not understood by local communities is not a new phenomenon. Modern medicine in sub-Saharan Africa has identified people labelled as witches, who in fact had long term conditions, such as: Huntington's disease (Loi \& Chiu, 2012), Parkinson's disease (Mokaya, Gray, \& Carr 2017), and epilepsy (Maiga et al., 2014). Accusations of witchcraft and the social stigma attached has implications on health seeking behaviours of those with diseases who have symptoms that are misunderstood. People who believe their symptoms to be 'beyond human control' will not seek advice, care or support from modern healthcare (Guerchat et al., 2017), but seek health care from faith and traditional healers. Faith healers, usually belong to one of the independent African churches, and aim to heal a patient through prayer, applying holy water and touching the person, whereas traditional healers are herbalists who aim to heal a patient through the provision of curative herbs and medicines of animal origin (Kings Fund, 2008).

One disease; which affects a person's behaviours that may be misunderstood, is dementia. The risk of dementia increases with age (Corrada et al., 2010), and neuropsychiatric symptoms of dementia, such as depression, anxiety, and irritability, are significantly more common in women than in men living in one of two countries in Central Africa (Yoro-Zhoun et al., 2019). Therefore, there is a strong possibility in sub-Saharan Africa that older women with dementia are at a greater risk of abuse and harm due to accusation of witchcraft. This risk is elevated due to a lack of awareness of dementia, and the neuropsychiatric symptoms of dementia in rural communities (Benade, 2012; de Jager, et al. 2015).

Dementia is an umbrella term for certain progressive and life-limiting diseases of the brain. The three most common types of dementia are Alzheimer's disease, vascular dementia and Lewy Bodies dementia (Goodman et al., 2017). The International Statistical Classification of 
Disease and Related Health Problems, tenth addition (World Health Organisation, 2016) provides the following clinical information and description of dementia:

“... a disturbance of multiple higher cortical functions, including memory, thinking, orientation, comprehension, calculation, learning capacity, language, and judgement. Consciousness is not clouded. The impairments of cognitive function are commonly accompanied, and occasionally preceded, by deterioration in emotional control, social behaviour, or motivation."

The prevalence of dementia in sub-Saharan Africa ranges from 2.3\% to $21.6 \%$, (Olayinka \& Mbuyi, 2014). Previously, the prevalence of dementia in sub-Saharan Africa was estimated to be lower than Western countries, but recent data suggests prevalence is in fact parallel (Longdon et al., 2012), if not higher (de Jager, Msemburib, Pepperc, \& Combrincka, 2017). However, there is a paucity of research exploring the prevalence and incidence of dementia in Africa, and the need for epidemiological studies remains (Olayinka \& Mbuyi, 2014; de Jager et al., 2017). An element that may be more relevant in African countries is the prevalence of HIV associated dementia (HAD), as prevalence of HAD ranges from $15 \%$ to $30 \%$ in populations where the disease has gone untreated (Grant, 2008).

Culturally sensitive services to support people with dementia in Africa have commenced, although these are small scale with limited resources (Benade, 2012). Due to the limited resources and interventions in sub-Saharan Africa, people living with dementia in this region have a mortality risk 2.5 times higher than people without cognitive impairment (Samba, et al., 2016). In addition, there are anecdotal reports, which suggest witch camps include a large number of people with dementia, who are living in extremely poor and harsh conditions.

\section{AIM}

The aim of this systematic review is to explore the cultural belief of 'dementia is witchcraft' and the impact of this belief on healthcare providers, people with dementia and their families in sub-Saharan Africa.

\section{METHODS}

A systematic review was completed following the Preferred Reporting Items for Systematic Reviews and Meta-Analyses (PRISMA) guidelines (Moher, Liberati, Tetzlaff, \& Altman, 2009). Please refer to Supplementary File 1 for the completed PRISMA checklist.

Search Strategy 
The following electronic databases were searched from inception to $31^{\text {st }}$ May 2019: CINHAL, PsychINFO, Web of Knowledge, PubMed and Science Direct. Search strategies were tailored for each database and included recognised Medical Subject Headings (MeSH), with Boolean operators of AND and OR. For example the following was applied to search CINHAL: "dementia or alzheimers or cognitive impairment or memory loss" AND "witchcraft" OR "witchcraft in Africa" OR "witches".

The review process also included a hand search of a number of prominent journals in dementia, although no specific journals on witchcraft or cultural and spiritual elements of sub-Saharan Africa were identified. Following the search for literature, screening of the reference lists of all identified material was manually completed.

Inclusion and Exclusion Criteria

Inclusion criteria were studies presenting primary data related to dementia and witchcraft in sub-Saharan Africa published in peer reviewed journals from inception to 31st May 2019 in the English Language. Exclusion criteria were studies presenting primary data focusing on witchcraft and older women in sub-Saharan Africa with no inclusion of dementia, non-peer reviewed publications, such as newspaper articles and reports.

\section{Data Extraction}

The first author extracted the following data from each study: reference, aim, data collection and analysis, participants, results and discussion. The second author checked the accuracy of the data extracted, and discrepancies were resolved through discussion.

Data Synthesis

Data synthesis occurred through the analysis of extracted data to identify emergent themes. Due to the different approaches and focus of the included studies, a thematic synthesis of the data was completed. The authors adhered to three stages of thematic synthesis as described by Thomas and Harden (2008). The first stage included the coding of extracted data, this process was completed by both authors and included line by line coding of extracted data according to its meaning and content. The process of line-by-line coding is an essential element in the process of synthesis of qualitative data, which supports the translation of concepts (Britten et al., 2002). The second stage involved the expansion of coding, by grouping codes together and the development of new codes to capture the meaning of each group of codes. The first two stages of analysis remain embedded in the analysis of the primary data, whereas the third stage involved an interpretative phase to develop analytical themes. The third stage developed additional concepts, knowledge and 
understanding from the primary data. The first author completed the three stages of analysis, and then discussed in depth with the second author.

\section{FINDINGS}

Study selection

Relevant papers were identified through the application of the inclusion and exclusion criteria; this process is summarised in the PRISMA diagram (Moher et al., 2009). Due to the small amount of papers identified $(n=71)$, all abstracts were screened; this process was important as few papers focused on witchcraft and dementia, the majority focused on dementia with the element of witchcraft reported within the results of the study as an incidental finding. Full papers were then obtained $(n=14)$, of which five met the inclusion and exclusion criteria (refer to Diagram 1).

Quality Assessment

A number of quality assessment tools were applied to appraise the included studies, the CASP checklist for qualitative studies (CASP, 2018) for Mushi et al. (2014), Hindley et al. (2016), Mkhonto \& Hanssen (2018) and Kehoua et al. (2019), and a critical cross-sectional appraisal tool (Downes, Brennan, Williams, \& Dena, 2016) for Khonje et al. (2015). Overall, the qualitative studies were robust in nature. One study presented rigorous translation and transcription processes, although the analysis was completed by one author, therefore the development of themes was not crosschecked by another member of the team (Hindley et al., 2016). The only cross-sectional study, was representative of the population studied, however the Alzheimer's disease quiz (Ayalon \& Arean, 2004) was adapted, which the authors stated was necessary to support the needs of their participants, although the reliability and validity of the adapted questionnaire was not reported (Khonje et al., 2015). Furthermore, the application of the questionnaire was through isiXhosa translators who accompanied the English-speaking researchers, although there is no information on the consistency of translations that occurred (Khonje et al., 2015).

\section{Study Characteristics}

Studies were completed in Tanzania (Hindley et al., 2016; Muschi et al., 2014), Republic of Congo (Kehoua et al., 2019), and South Africa (Mkhonto \& Hanssen, 2018; Khonje et al., 2015). Studies included the exploration of: community knowledge, attitudes and experiences of people with dementia (Muschi et al., 2014; Khonje et al., 2015); understanding traditional healers and Christian faith healers knowledge of dementia and how to support people with dementia (Hindley et al., 2016), and the cultural beliefs of people with dementia, family members, nurses, traditional healers and church leaders regarding dementia as witchcraft 
(Mkhonto \& Hanssen, 2018; Kehoua et al., 2019). Refer to Table 1 for further details of each study.

\section{Study Designs}

Qualitative data collection methods included semi-structured interviews (Muschi et al., 2014; Hindley et al., 2016), narrative interviews (Mkhonto \& Hanssen, 2018) and non-directive interviews and participant observations (Kehoua et al. 2019). Quantitative data collection methods included the Alzheimer's disease Knowledge Scale (Carpenter, Balsis, Otilingam, Hanson, \& Gatz, 2009) and open and closed questions of a questionnaire adapted from the Alzheimer's disease quiz (Ayalon \& Arean, 2004), which included sections on: knowledge, attitudes, experiences and practices towards people with dementia (Khonje et al., 2015).

Participants

The number of participants within the qualitative studies ranged from $8-66$, with a total of 227 , which included: nurses $(n=10)$, family member caring for a person with dementia $(n=97)$, people with dementia ( $n=81)$, traditional healers $(n=17), G P(n=1)$, and Christian faith healers $(n=18)$. The quantitative cross-sectional study recruited 100 community members living in the township of Khayelitsha, of whom 68\% were women (Khonje et al., 2015).

\section{Themes}

Three themes emerged from the analysis: 1) poor knowledge of dementia and the belief of dementia as witchcraft; 2) challenges of supporting a person with dementia in the community; 3) health seeking behaviour of and for people with dementia.

\section{Poor knowledge of dementia and the belief of dementia as witchcraft}

People living in the community did not recognise or understand the term dementia, and therefore the disease could not be described (Mushi et al., 2014). Similarly, faith healers and traditional healers did not know the word dementia, although understood the symptoms of dementia (Hindley et al., 2016). Nurses working in a care home also acknowledged a lack of understanding of dementia prior to commencing their current role, however caring for people with dementia supported the development of their knowledge (Mkhonto \& Hanssen, 2018).

Beliefs of dementia and the causes of dementia could be contradictory and held simultaneously. Khonje et al. (2015) found participant's $(n=100)$ believed dementia was related to witchcraft (28\%), punishment from ancestors (18\%) or God (14\%), although $87 \%$ accurately understood dementia to be a disease of the brain. Faith healers and traditional healers believed the causes of dementia included witchcraft, possession by devils, ancestral 
problems and punishment by god, but also: aging, other diseases and stress (Hindley et al., 2016).

Witchcraft was associated with people who demonstrated strange and abnormal behaviours according to community norms (Mkhonto \& Hanseen, 2018). Informal family caregivers living in urban (68.4\%) and rural (26.9\%) areas identified accusations of witchcraft against their relative, due to these accusations families suffered physical, psychological and financial abuse (Kehoua et al. 2019). When a person who had been accused of witchcraft or being a witch was diagnosed with dementia, they were still believed to be dangerous, violent and needed to be avoided (Khonje et al., 2015). Beliefs of witchcraft also caused people to fear people with dementia and fear for their property (Mkhonto \& Hanseen, 2018).

\section{Challenges of supporting a family member with dementia in the community}

Challenges of caring for a family member with dementia in the community included: not knowing how to provide care, the concern that someone with dementia would not cooperate and receive care, and the person with dementia would cause destruction to the family home if left alone (Khonje et al., 2015). The constant worry of not leaving a person with dementia alone needed to be balanced with keeping them safe and the need for the family caregiver to complete other activities outside of caring. The balance of keeping the person with dementia safe, while the family caregiver was not at home led to the person with dementia occasionally being locked alone inside the family home (Muschi et al., 2014).

A further challenge for family members providing care was the isolation that the situation created. Family members reported communities and their own relatives would not support them to care for the person with dementia, due to fear and cultural beliefs of dementia as witchcraft (Mkhonto \& Hanseen, 2018). Nurses feared for people with dementia, as they identified physical abuse, which occurred to people with dementia whilst living in the community, due to the community's belief that the patient was a witch, therefore the care home was a necessary and safe place for them to receive care (Mkhonto \& Hanseen, 2018).

Health seeking behaviour of and for people with dementia

Health seeking behaviours overlapped with participant's beliefs of dementia; $54 \%$ sought help from modern healthcare providers, 32\% from faith healers, and 15\% from traditional healers (Mushi et al., 2014). Help from traditional and faith healers were more likely to be sought if their beliefs of the cause of dementia included witchcraft or punishment from God (Khonje et al., 2015). Traditional healers provided treatment with unknown herbs, whilst faith healers provided prayers and medication, and those who believed dementia was related to witchcraft reported an improvement in their symptoms, but not a cure (Hindley et al., 2018). 
Health seeking behaviour was also pluralistic, $73 \%$ of people with dementia reported seeking help from more than one source, although modern care and faith healers were reported as more being the most effective (Muschi et al., 2014). The pluralistic nature of healthcare was discussed, as faith healers and some participants were concerned traditional healers would not support collaboration with modern care (Hindley et al., 2016). Traditional healers reported they would not refer people with dementia to modern care because the cause of dementia was witchcraft and 'doctors cannot manage witchcraft'; this belief was congruent for some people with dementia and their family members (Hindley et al., 2016).

The complex nature of pluralistic health seeking behaviours are not consistent across urban and rural areas in the Republic of Congo (Kehoua et al. 2019). Informal family caregivers living in urban communities first sought care for the person with dementia from church leaders (68.4\%), and when the treatment provided was unsuccessful, sought care from traditional healers (26.3\%). Whereas, informal family caregivers living in rural areas first sought care from traditional healers $(58.5 \%)$, and then church leaders $(29.4 \%)$. Only one person with dementia living in the urban area visited a GP, and two people living with dementia in the rural area were admitted to hospital, suggesting a lack of collaboration between church leaders, traditional healers and modern healthcare provision across both urban and rural areas.

\section{DISCUSSION}

Three broad themes emerged from the literature. First was the overall poor knowledge of dementia and the belief of dementia as witchcraft, this involved the holding of incongruent beliefs such as an accurate understanding of dementia as a disease of the brain and dementia as witchcraft. Secondly, the challenges of supporting a family member with dementia in the community with dementia was related to a lack of understanding on how to provide care, and the isolation caused by the stigma of dementia as witchcraft. Lastly, health-seeking behaviour of and for people with dementia was pluralistic in nature, supporting underlying beliefs of dementia as witchcraft but also seeking modern care. Therefore, in order to ameliorate these challenges three key strategies have been developed and are discussed below.

Need for dementia education

Poor knowledge and misconceptions of dementia were identified in this review, and these were found amongst people with dementia, their families, nurses, faith and traditional healers. Contemporary research supports this finding, as participants from Africa and Asia had significantly less knowledge of cognitive decline and dementia compared to those from 
Europe, US and Canada, even when education levels were accounted for (van Patten \& Tremont, 2018). Therefore, there is a need for education and training of nurses and other healthcare professionals to support diagnosis, treatment and care, alongside public awareness of dementia as a biological disease.

Health awareness and education of dementia needs to commence with the introduction of the term dementia, as there is no equivalent term in many of the local languages in subSaharan Africa (Faure-Dalage et al. 2012; Muschi et al. 2014; Hindley et al. 2016). The introduction of the term of dementia and the symptoms of dementia from a modern healthcare perspective can begin to challenge the beliefs of dementia as a condition that is 'beyond human control' (Guerchat et al., 2017). Challenging cultural beliefs of dementia needs to occur to support the understanding of dementia as a medical condition, which to be diagnosed, treated, and the implementation of long-term support from healthcare professionals.

The delivery of health education and promotion in sub-Saharan Africa to support public awareness and education of dementia is possible through previously applied frameworks. Currently health education has focused on providing knowledge to prevent diseases, such as cardiovascular disease, hypertension and diabetes (Abanilla et al., 2011; Cappuccio, Kerry, Micah, \& Plange-Rhule, 2006). These health education interventions were successful due to their approach of engaging with local communities, Abanilla et al. (2011) implemented a cardiovascular disease prevention programme within faith-based organisations, while Cappuccio et al. (2006) obtained the endorsement of local chiefs and community leaders to support a programme to reduce salt intake. When considering how to improve public awareness and understanding of dementia, engagement with faith and traditional healers as well as local chiefs and community and church leaders is essential to support the awareness of dementia as a biological disease throughout communities in sub-Saharan Africa, and begin the process of disconnecting the symptoms of dementia with witchcraft.

Need for community support to care for a person with dementia

Family members caring for someone with dementia in Tanzania and South Africa lacked the necessary knowledge and skills, which demonstrates a need for community based services to inform and support both the person with dementia and their family members. Cognitive stimulation therapy (CST), although developed in high income countries is a low-resource non-pharmacological strategy for people with dementia that improves quality of life, cognition and reduces dependence on community support (Augiree et al., 2014). The implementation of CST for all people with dementia regardless of the income status of the country is essential (Prince, Albanese, \& Guerchet 2014). CST is a programme that engages with 
people with dementia through respect and activities that stimulate discussions, promoting learning and the formation of new neuronal connections (Hall, Orrell, Stott, \& Spector, 2013). A feasibility study for the adaptation of CST for use in Tanzania and Nigeria found substantial improvement in participant's cognition and behavioural symptoms (Mkenda et al., 2011). Therefore, there is tentative support and evidence for CST in sub-Saharan Africa as a low-cost sustainable approach to support people with dementia and their families.

Need for a pluralistic approach to dementia

The pluralistic approach to health seeking behaviours identified in this review from modern care, faith healers, traditional healers and church leaders is a recognised approach in SubSaharan Africa (Gurechat et al. 2017). Medical pluralism or pluralistic healthcare is the coexistence of multiple health care providers within one geographical location (World Health Organisation, 2013). Pluralistic healthcare in Ghana has been widely acknowledged with biomedical and traditional healthcare existing in parallel, but simultaneously integrated by patients (Moshabela, Schneider, Silal, \& Cleary, 2012; Sato, 2012).

Pluralistic healthcare can impact negatively on patient outcomes due to delayed diagnosis and appropriate treatment. The exploration of collaboration between modern healthcare and traditional healthcare within the provision of biomedical HIV treatment, found the need to support both a patient's spiritual needs and biomedical needs (Audet, Ngobeni, \& Wagner, 2017; Zuma, Wight, Rochat, \& Moshabela, 2018). Therefore, highlighting the importance of maintaining an integrated approach to support a patient's health and well-being (Zuma et al., 2018). An integrated care model to support people living with dementia and their families across sub-Saharan Africa has yet to be developed. Further research to support the understanding of how to integrate traditional and modern healthcare for people with dementia and their families', whilst addressing cultural beliefs of dementia is urgently required.

The effectiveness of an integrated approach depends on the education of traditional healthcare providers, with the inclusion of when it is appropriate and necessary to refer patients to biomedical services (Audet et al., 2017). The education needs of traditional and biomedical healthcare providers regarding dementia is essential to address to support an integrated pluralistic healthcare approach to support people with dementia and their families. An integrated pluralistic healthcare approach in dementia is especially important including supporting the biomedical aspect of dementia and the psychosocial impact on the person with dementia and their family members.

Limitations 
Only papers published in the English language were included in this review, which due to the subject matter is a limitation. However, this review highlighted a number of abstracts presented at international conferences exploring dementia in Africa, although no full papers from these streams of work were found. The abstracts explored dementia sensory simulation training in Kenya (Chira Kangethe, \& Mutunga, 2016), and the challenges of obtaining healthcare by people with dementia in Ghana (Spittel \& Wolf-Ostermann, 2013). Therefore, there is a need for these research studies to be published beyond that of an abstract.

\section{CONCLUSION}

The results of this review identify the need to progress beyond a focus on the prevalence, incidence and risk factors of dementia in sub-Saharan Africa. There is now an urgent need to explore the diagnosis, treatment and care of people with dementia in sub-Saharan Africa. This includes the need for community support through low-resource interventions such as CST, a pluralistic approach to providing healthcare and public education, all of which need to challenge cultural beliefs of dementia as witchcraft to support a reduction in stigma and an increase in support for people living with dementia and their families.

\section{RELEVANCE TO CLINICAL PRACTICE}

Nurses are the best-placed healthcare professionals to support the dissemination and implementation of dementia awareness and non-pharmacological interventions to support people with dementia and their families to remain living well in the community. However, this review identified the lack of knowledge and understanding of some healthcare professionals of dementia until working with patients with dementia, therefore the inclusion of dementia in undergraduate nurse training is essential. Nurses and those caring for patients can only provide person-centred care and support for a person with dementia and their family if they understand their cultural beliefs.

\section{Funding}

No funding was obtained to complete this work.

\section{Ethical approval}

No ethical approval was required for this research.

\section{Acknowledgements}

None to declare

\section{Author Contributions}


The first author conceived and designed the study, and completed the initial search. The first and second author both contributed and worked closely on the extraction of data, analysis and writing of the paper.

\section{References}

Abanilla, P.K., Huang, K-Y., Shinners, D., Levy, A., Ayernor, K., de-Graft Aikins, A., Ogedegbe, O. (2011). Cardiovascular disease prevention in Ghana: feasibility of a faithbased organizational approach. Bulletin of the World Health Organisation, 89, 648-656.

\section{http://doi.org/10.2471/BLT.11.086777}

Aboderin, I.A.G., Beard, J.R. (2015). Older people's health in sub-Saharan Africa. Lancet, 385, e9-e11. https://doi.org/10.1016/S0140-6736(14)61602-0

Aguirre, E., Spector, A., Orrell, M. (2014). Guidelines for adapting cognitive stimulation therapy to other cultures. Clinical Interventions in Aging, 9, 1003-1007.

https://doi.org/10.2147/CIA.S61849

Appiah, K.A. (1991). In my Father's house: Africa in the philosophy of culture. Oxford: Oxford University Press.

Ashforth, A. (1998). Reflections on spirituality insecurity in a modern African city (Soweto). African Studies Review, 41, 39-67.

Atata, S.N. (2018). Aged women, witchcraft, and social relations among the Igbo in SouthEastern Nigeria. Journal of Women and Aging, https://doi.org/10.1080/08952841.2018.1436415.

Audet, C.M., Ngobeni, S., Wagner, R.G. (2017). Traditional healer treatment of HIV persists in the era of ART: a mixed methods study from rural South Africa. BMC Complementary and Alternative Medicne 17, 434. https://doi.org/10.1186/s12906-017-1934-6 
Ayalon, L., Areán, P.A. (2004). Knowledge of Alzheimer's Disease in Four Ethnic Groups of Older Adults. International Journal of Geriatric Psychiatry, 19, 51-57.

\section{http://dx.doi.org/10.1002/gps.1037}

Bastian, M.L. (2002). "The daughter she will eat agousie in the world of the spirits":

Witchcraft confessions in missionised Onitsha, Nigeria. Africa (London), 72, 84-111.

https://doi.org/10.3366/afr.2002.72.1.84

Benade, S. (2012). Support services for people suffering from dementia in the rural areas of Kwa-Zulu Natal, South Africa. Dementia (London), 275-277.

\section{https://doi.org/10.1177/1471301212437458}

Britten, N., Campbell, R., Pope, C., Donovan, J., Morgan, M., Pill, R. (2002). Using metaethnography to synthesise qualitative research: a worked example. Journal of Health Service and Research Policy, 7:209-215. https://doi.org/10.1258/135581902320432732

Cappuccio, F.P., Kerry, S.M., Micah, F.B., Plange-Rhule, J., Eastwood, J.B. (2006). A community programme to reduce salt intake and blood pressure in Ghana [ISRCTN88789643]. BMC Public Health, 6, 13. https://doi.org/10.1186/1471-2458-6-13

Carpenter, B.D., Balsis, S., Otilingam, P.G., Hanson, P.K., Gatz, M. (2009). The Alzheimer 's disease Knowledge Scale: Development and Psychometric Propertis. Gerontologist, 49, 236-247. http://dx.doi.org/10.1093/geront/gnp023

Chira, S.M., Kangethe, D.N., Mutunga, E. (2016). Impact of experiential sensory stimulation training creating dementia awareness and reducing stigma in rural communities in Kenya. Alzheimer's \& Dementia Journal, 12, 1130-1131. https://doi.org/10.1016/j.jalz.2016.06.2355

Corrada, M., Brookmeyer, R., Paganini-Hill, A., Berlau, D., \& Kawas, C. (2010). Dementia incidence continues to increase with age in the oldest old: the 90+ study. Annals of Neurology, 67, 114-121. https://doi:10.1002/ana.21915 
Crampton, A. (2013). No Peace in the House: Witchcraft accusations as an "Old Women's Problem" in Ghana. Anthropology and Aging Quarterly, 34, 199-212.

\section{https://doi:10.5195/aa.2013.20}

Critical Appraisal Skills Programme, CASP (Qualitative) Checklist. https://casp-uk.net/wpcontent/uploads/2018/01/CASP-Qualitative-Checklist.pdf 2018 (accessed 4 January 2019).

de Jager, C.A., Joska, J.A., Hoffman, M., Borochowitz, K.E., Combrinck, M.I. (2015). Dementia in rural South Africa: A pressing need for epidemiological studies. South Africa Medical Journal, 105, 189-190. https://doi:10.7196/SAMJ.8904

de Jager, C.A., Msemburib, W., Pepperc, K., Combrincka, M.I. (2017). Dementia Prevalence in a Rural Region of South Africa: A Cross-Sectional Community Study. Journal of Alzheimers Disease, 60, 1087-1096. https://doi.org/10.3233/JAD-170325

Downes, M.J., Brennan, M.L., Williams, H.C., Dena, R.S., (2016). Development of a critical appraisal tool to assess the quality of cross-sectional studies (AXIS). BMJ Open 6, e011458. http://dx.doi.org/10.1136/bmjopen-2016-011458

Faure-Delage, A., Mouanga, A.M., M'belesso, P., Tabo, A., Bandzouzi, B., Dubreuil. C-M., Preux, P-M., Clément, J-P., Nubukpo, P. (2012). Socio- cultural perceptions and representations of Dementia in Brazzaville, Republic of Congo: The EDAC Survey. Dementia and Geriatric Cognitive Disorders. http://doi:10.1159/000335626

Guerchet, M., Mayston, R., Lloyd-Sherlock. P., Prince, P., Aboderin, I., Akinyemi, R., Paddick, S-M., Wimo, A., Amoakoh-Coleman, M., Uwakwe, R., Ezeah, P. (2017). Dementia in sub-Saharan Africa: Challenges and Opportunities. Alzheimer's Dementia International, UK: London.

Goodman, R.A., Lochnerc, K.A., Thambisettyd, M., Wingoe, T.S., Posnera, S.F., Ling, M. (2017). Prevalence of dementia subtypes in United States Medicare fee-for-service 
beneficiaries, 2011-2013. Alzheimers and Dementia Journal, 13, 28-37.

https://doi.org/10.1016/i.jalz.2016.04.002

Hall, L., Orrell, M., Stott, J., Spector, A. (2013). Cognitive stimulation therapy (CST):

Neuropsychological mechanisms of change. International Psychogeriatrics, 25, 479-489.

https://doi.org/10.1017/S1041610212001822

Hindly, G., Kissima, J., Oates, L.L., Paddick, S-M., Kisoli, A., Brandsma, C., Gray, W.K., Walker, R.W., Muschi, D., Dotchin, C. (2016). The role of traditional and faith healers in the treatment of dementia in Tanzania and the potential for collaboration with allopathic healthcare services. Age and Ageing, 46, 130-137. https://doi.org/10.1093/ageing/afw167

Kehoua, G.T.C., Dubreuil, C-M., Bandzouzi, B.N., Guerchet, M., Mbelesso, P., Dartigues, JF., P-M. Preux, P-M. (2019). Stigmatizing attitudes of relatives against people suffering from dementia in urban and rural areas of Republic of Congo: An epdiemca-fu result. Alzheimer's and Dementia Journal, 11, 592. https://doi.org/10.1016/j.jalz.2015.06.805

Khonje, V., Milligan, C., Yako, U., Mabelane, M., Borochowitz, K.E., de Jager, C.A. (2015). Knowledge, attitudes and beliefs about dementia in Urban Xhosa-speaking community in South Africa. Advances in Alzheimer's disease, 4, 21-36.

http://dx.doi.org/10.4236/aad.2015.42004

Krug, E.G., Dahleberg, L.L., Mercy, J.A., Swi, A.B., Lonzano, R. (2002). World Report on violence and health. Geneva: World Health Organisation.

Loi, S., Chui, E. (2012). Witchcraft and Huntington's disease: a salutary history of societal and medical stigmatisation. Australasian Psychiatry, 20, 438-441.

https://doi.org/10.1177/1039856212459587

Longdon, A.R., Paddick, S.M., Kisoli, A., Dotchin, C., Gray, W.K., Dewhurst, F., Chaote, P., Teodorczuk, A., Dewhurst, M., Jusabani, A.M., Walker, R. (2013). The prevalence of 
dementia in rural Tanzania: a cross-sectional community-based study, International Journal of Geriatric Psychiatry 28, 728-37. https://doi.org/10.1002/gps.3880

Maiga, Y., Albakaye, M., Diallo, L.L., Traoré, B., Cissoko, Y., Hassane, S., Diakite, S., McCaughey, C., Kissani, N., Diaconu, V., Buch, D., Kayentoa, K., Carmant, L. (2014). Current beliefs and attitudes regarding epilepsy in Mali. Epilepsy and Behaviour, 33, 115121. https://doi.org/10.1016/i.yebeh.2014.02.031

MakkiAwouda, F.O., Elmukashfi, T.A., Hag Al-Tom, S.A. (2014). Effects of health education of diabetic patient's knowledge at Diabetic Health Centers, Khartoum State, Sudan: 20072010. Global Journal of Health Science, 6, 221-226.

\section{http://dx.doi.org/10.5539/gihs.v6n2p221}

Mkenda, S., Olakehinde, O., Mbowe, G., Siwoku, A., Kisoli, A., Paddick, S.M., Adediran, B., Gray, W.K., Dotchin, C.L., Adebiyi, A., Walker, R.W., Mushi, D., Ogunniyi, A. (2018). Cognitive stimulation therapy as a low-resource intervention for dementia in sub-Saharan Africa (CST-SSA): Adaptation for rural Tanzania and Nigeria. Dementia (London), 17, 515530. https://doi.org/10.1177/1471301216649272

Mkhonto, F., Hanssen, I. (2018). When people with dementia are perceived as witches. Consequences for patients and nurse education in South Africa. Journal of Clinical Nursing, 27, e169-e176. https://doi.org/10.1111/jocn.13909

Moher, D., Liberati, A., Tetzlaff, J., Altman, D.G. (2009). The PRISMA Group. Preferred Reporting Items for Systematic Reviews and Meta-Analyses: The PRISMA Statement, PLoS Med, 6, e1000097. https://doi.org/10.1371/journal.pmed.1000097

Mokaya, J., Gray, W.K., Carr, J. (2017). Beliefs, knowledge and attitudes towards Parkinson's disease among a Xhosa speaking black population in South Africa: A crosssectional study. Parkinsonism and Related Disorders, 41, 51-57. https://doi.org/10.1016/i.parkreldis.2017.05.009 
Moshabela, M., Schneider, H., Silal, S.P., Cleary, S.M. (2012). Factors associated with patterns of plural healthcare utilization among patients taking antiretroviral therapy in rural and urban South Africa: A cross-sectional study, BMC Health Service Research, 12, $182-$ 192. https://doi.org/10.1186/1472-6963-12-182

Mouton, C.P., Southerland, J.H. (2017). Elder Abuse in the African Diaspora: A Review. Journal of the National Medical Association, 109, 262-271.

https://doi.org/10.1016/i.jnma.2017.08.006

Mushi, D., Rongai, A., Paddick, S-M., Dotchin, C., Mtuya, C., Walker, R. (2014). Social representation and practices related to dementia in Hai District of Tanzania. BMC Public Health, 14:260. https://doi.org/10.1186/1471-2458-14-260

Ndamba-Bandzouzi, B., Nubukpo, P., Mouanga, A., Mbelesso, P., Tognide, M., Tabo, A., Guerchet, M., Fauredelage, A., Dubreuil, C-M., Dassa, V., Dumas, M., Clement, J-P., Preux, P.M. (2014). Violence and witchcraft accusations against older people in Central and Western Africa: toward a new status for the older individuals? International Journal of Geriatric Psychiatry, 29, 546-549. https://doi.org/10.1002/gps.4069

Olayinka, O.O., Mbuyi, N.N. (2014). Epidemiology of dementia among the elderly in subSaharan Africa. International Journal of Alzheimers Disorders, 195750.

https://doi.org/10.1155/2014/195750

Palmer, K. (2010). Spellbound: Inside West Africa's witch camps. New York: Free Press, 2010

Prince, M., Albanese, E., Guerchet, M. (2014). World Alzheimer Report 2014. London, England, Alzheimer Disease International.

Samba, H., Guerchet, M., Ndamba-Bandzouzi, B., Mbelesso, P., Lacroix, P., Dartigues, J-F., Preux, P-M. (2016). Dementia-associated mortality and its predictors among older adults in 
sub-Saharan Africa: results from a 2-year follow-up in Congo (the EPIDEMCA-FU study). Age and Ageing, 45, 681-687. https://doi.org/10.1093/ageing/afx011

Samber, N., Avanger, M.Y., Abanyam, N.L. (2014). Analysis of factors precipitating witchcraft accusation among the Tiv. Anthropologist, 18, 1077-1087.

https://doi.org/10.1080/09720073.2014.11891590

Sato, A. (2012). Does socio-economic status explain use of modern and traditional health care services? Social Science Medicine, 75, 1450-1459.

https://doi.org/10.1016/j.socscimed.2012.05.032

Saunders, T. (2003). Reconsidering Witchcraft: Postcolonial Africa and Analytic

(Un)Certainties. American Anthropology, 105, 338-352.

https://doi.org/10.1525/aa.2003.105.2.338

Simmons, W. (1980). Powerless, exploitation, and the soul-eating witch: An analysis of Bedyaranke Witchcraft. American Ethnologist, 7, 447-465.

https://doi.org/10.1525/ae.1980.7.3.02a00040

Spittel, S., Wolf-Ostermann, K. (2013). Challenges in health in care for people with dementia in Ghana, Alzheimers and Dementia Journal, 9, 488.

https://doi.org/10.1016/j.jalz.2013.05.998

The Kings Fund (2008). Regulating complementary medical practitioners.

https://www.kingsfund.org.uk/sites/default/files/regulating-complementary-medicalpractitioners-case-studies-anna-dixon-mar08.pdf (accessed June 30th 2019).

Thomas, J., Harden, A. (2008). Methods for thematic synthesis of qualitative research in systematic reviews. BMC Medical Research Methodology, 8, 44.

https://doi.org/10.1186/1471-2288-8-45 
Van Patten, R., Tremont, G. (2018). Public knowledge of late-life cognitive decline and dementia in an international sample. Dementia (London).

http://doi.org/10.1177/1471301218805923

Witchcraft and Human Rights Information Network [WHRIN] (2013). 21st Century Witchcraft: Accusation and Persecution. Global Report. http://www.whrin.org/wp-

content/uploads/2014/03/WHRIN-UN-report small-FINAL.pdf (accessed January 12 2019).

World Alzheimer's Report. (2016). Improving healthcare for people living with dementia; coverage, quality and costs now and in the future.

https://www.alz.co.uk/research/WorldAlzheimerReport2016.pdf (accessed 14 January 2019).

World Health Organisation. (2013). Traditional Medicine Strategy 2014-2023.

http://apps.who.int/iris/bitstream/10665/92455/1/9789241506090 eng.pdf?ua=1 (accessed 21 January 2019).

World Health Organization. (2016). ICD-10: international statistical classification of diseases and related health problems : tenth revision.

https://www.who.int/classifications/icd/icdonlineversions/en/ (accessed 14 January 2019).

Yoro-Zohoun, I., Nubukpo, P., Houinato, D., Mbelesso, P., Ndamba-Bandzouzi, B., Clément, J-P., Dartigue, J-F., Preux, P-M., Guerchet, M. (2019). Neuropsychiatric symptoms among older adults living in two countries in Central Africa (EPIDEMCA study). International Journal of Geriatric Psychiatry, 34, 169-178. https://doi.org/10.1002/gps.5006

Zuma, T., Wight, D., Rochat, T., Moshabela, M. (2018). Navigating multiple sources of healing in the context of HIV/AIDS and wide availability of antiretroviral treatment: a qualitative study of community participants'perceptions and experiences in rural South Africa. Front Public Health, 6, 73. http://doi.org/10.3389/fpubh.2018.00073 
Diagram 1: PRISMA flowchart

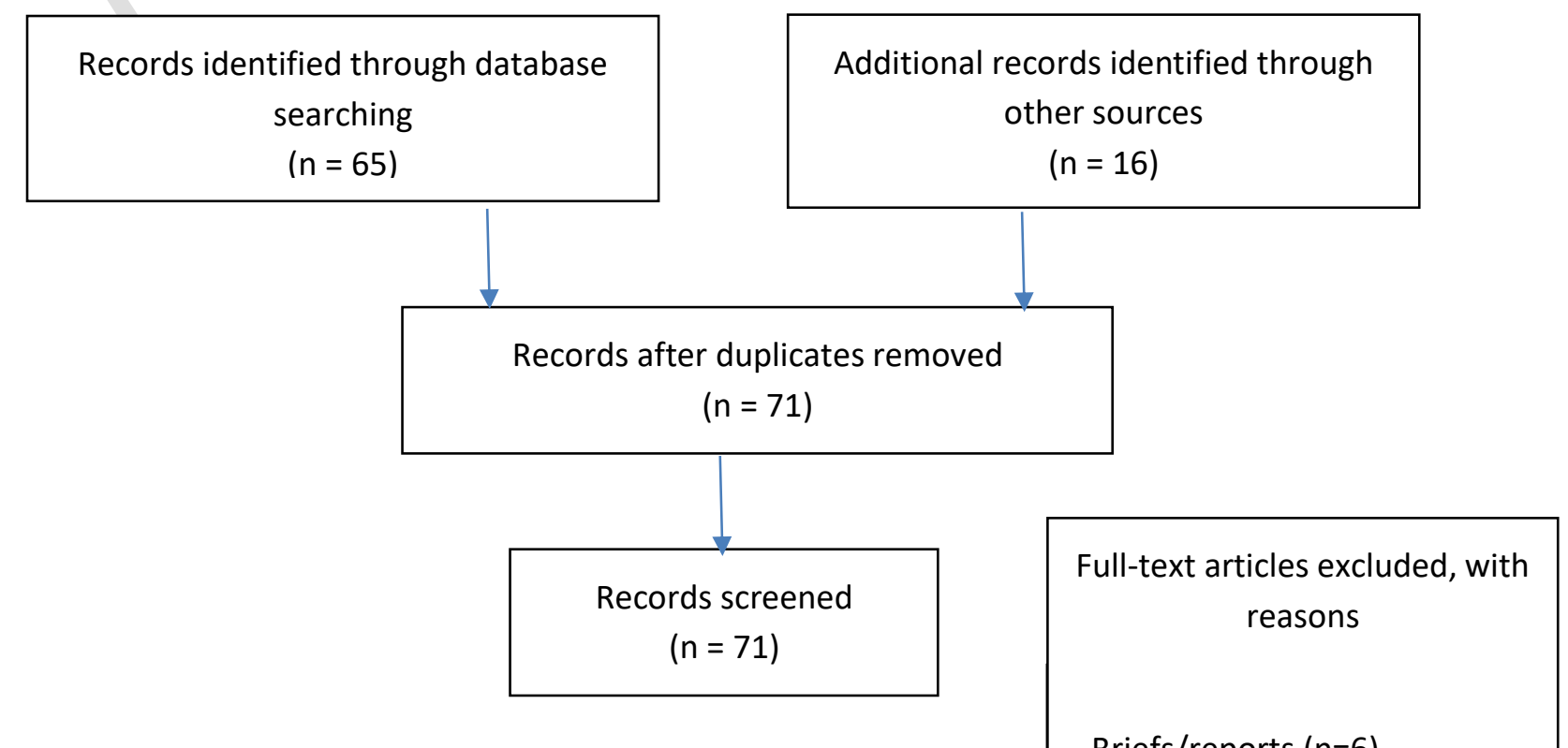




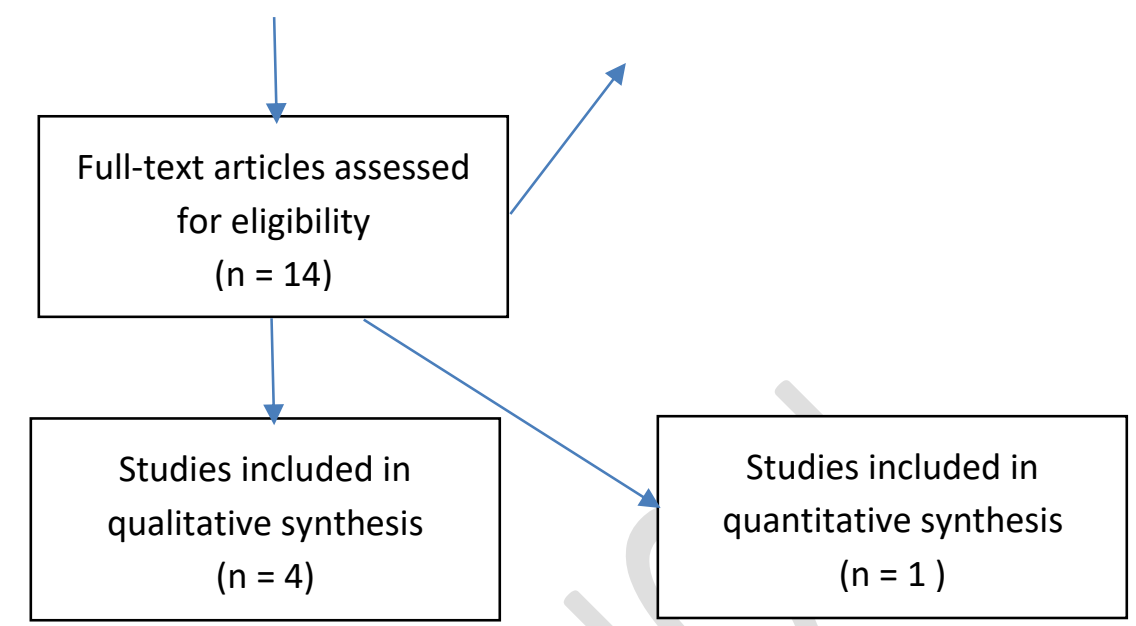

Adapted from Moher et al. (2009). 
Table 2: Overview of included papers

\begin{tabular}{|c|c|c|c|c|}
\hline $\begin{array}{l}\text { Author } \\
\text { Year } \\
\text { Country }\end{array}$ & Aim & $\begin{array}{l}\text { Data Collection } \\
\text { Data Analysis } \\
\text { Participants }\end{array}$ & Results & Discussion \\
\hline $\begin{array}{l}\text { Hindley et al. } \\
2016 \\
\text { Tanzania }\end{array}$ & $\begin{array}{l}\text { To explore how } \\
\text { traditional healers and } \\
\text { Christian faith healers } \\
\text { understand and manage } \\
\text { people with dementia } \\
\text { and why people with } \\
\text { dementia present to } \\
\text { these healers }\end{array}$ & $\begin{array}{l}\text { In-depth semi-structured } \\
\text { interviews } \\
\text { Convenience purposive- } \\
\text { stratified sample } \\
\text { Thematic analysis } \\
\text { Traditional healers ( } n=11) \\
\text { Christian faith healers ( } n=10) \\
\text { People with dementia }(n=18) \\
\text { Family caregivers ( } n=17)\end{array}$ & $\begin{array}{l}\text { Three themes emerged: } \\
\text {-conceptualisation of dementia by } \\
\text { healers as a normal part of the } \\
\text { ageing process } \\
\text {-people with dementia } \\
\text { and family members' reasons for } \\
\text { seeking help from healers was due } \\
\text { to the concern it was witchcraft } \\
\text { and the need for treatment, such } \\
\text { as prayers and herbs } \\
\text {-all participant were open to the } \\
\text { idea of collaboration with } \\
\text { allopathic healthcare services }\end{array}$ & $\begin{array}{l}\text { Traditional healers (TH) and faith } \\
\text { healers (FH) both identified the } \\
\text { cause of dementia as: old age, } \\
\text { other diseases, stress, witchcraft, } \\
\text { and possession by devils, } \\
\text { ancestral problems or God's } \\
\text { punishment. } \\
\text { FHs believed prayers would } \\
\text { improve a person's memory } \\
\text { problems, however TH would not } \\
\text { treat a person with herbs if they } \\
\text { thought their condition was due } \\
\text { to old age. } \\
\text { People with dementia visited THs } \\
\text { because they believed their } \\
\text { condition was due to witchcraft, } \\
\text { and obtained courses of unknown }\end{array}$ \\
\hline
\end{tabular}




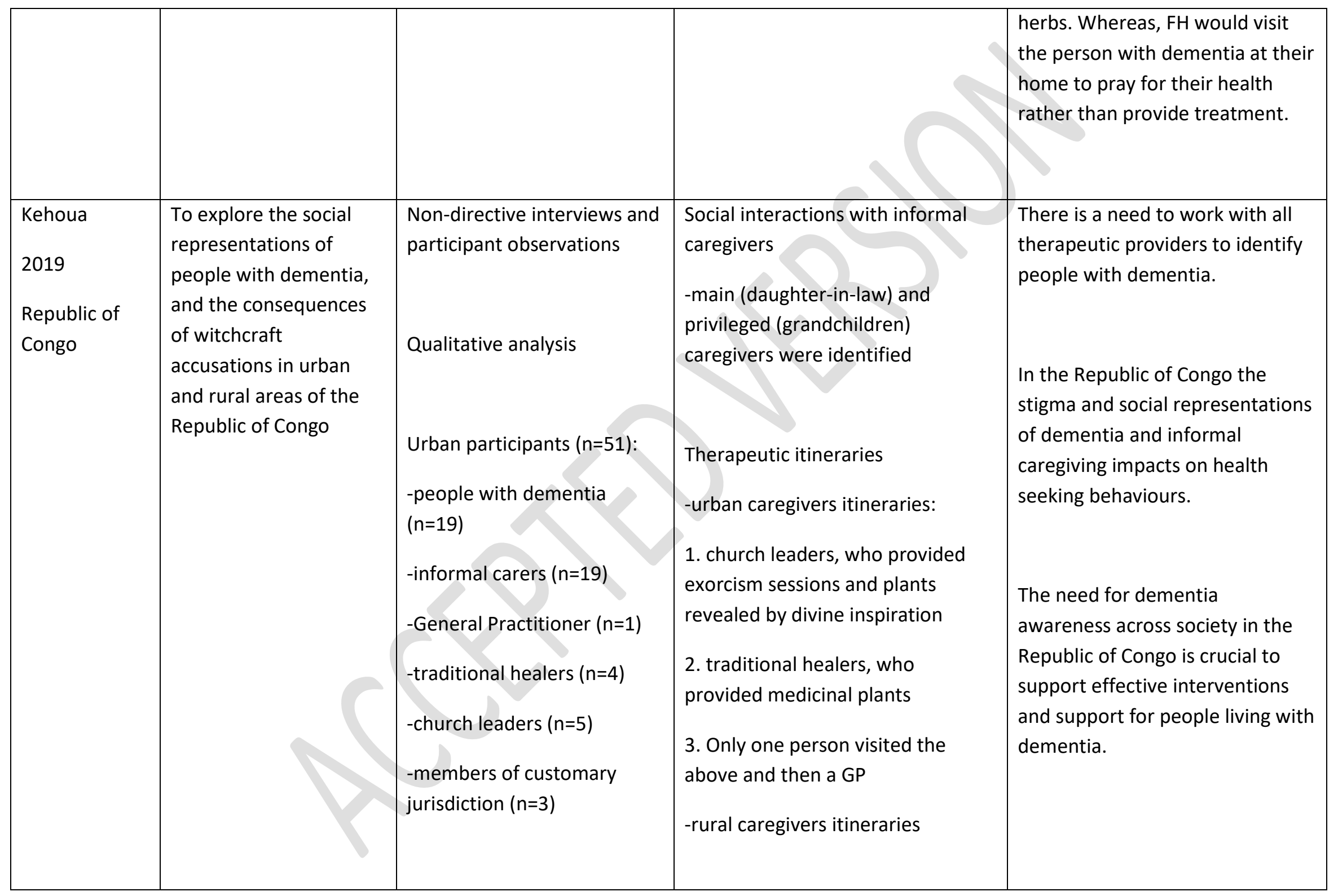




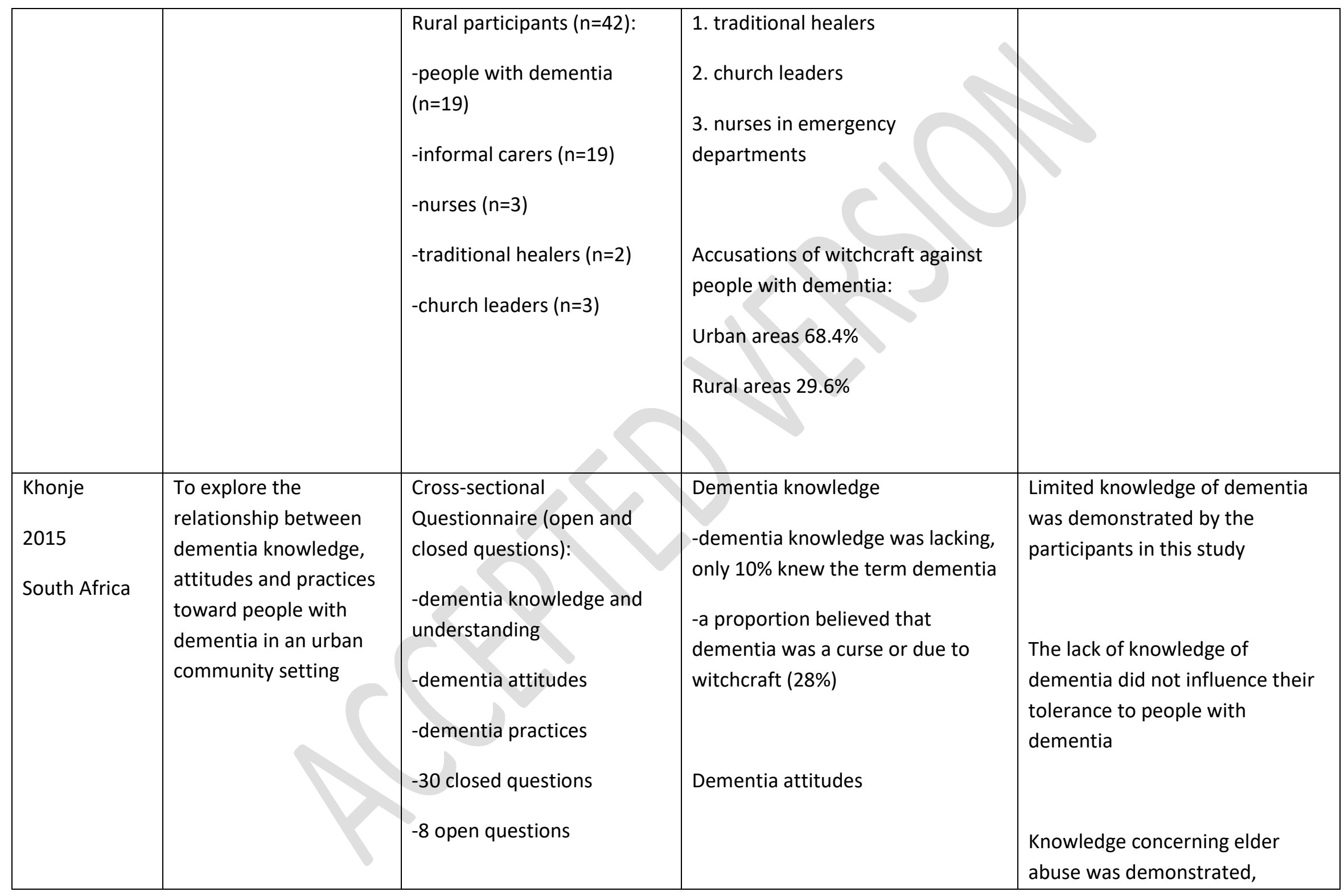




\begin{tabular}{|c|c|c|c|c|}
\hline & & $\begin{array}{l}\text { Descriptive statistics } \\
\text { Chi-squared tests to evaluate } \\
\text { relationships } \\
\text { Cluster sample }(n=100)\end{array}$ & $\begin{array}{l}\text {-participants would share their } \\
\text { house with a family member with } \\
\text { dementia ( } 88 \% \text { ) } \\
\text {-a proportion believed a person } \\
\text { with dementia was responsible for } \\
\text { their own illness ( } 7 \% \text { ) } \\
\text { Dementia practices } \\
\text {-participants reported not knowing } \\
\text { how to care for a person with } \\
\text { dementia } \\
\text {-elder abuse was understood (64\%) } \\
\text { and participants were able to } \\
\text { identify elder abuse ( } 97 \% \text { ) }\end{array}$ & $\begin{array}{l}\text { including indicates of abuse of } \\
\text { elders with dementia and } \\
\text { participants knew of community } \\
\text { services for abused elders } \\
\text { The importance of education } \\
\text { throughout the community } \\
\text { through workshops in schools, } \\
\text { halls, churches }\end{array}$ \\
\hline $\begin{array}{l}\text { Mkhonto and } \\
\text { Hanssen } \\
2018 \\
\text { South Africa }\end{array}$ & $\begin{array}{l}\text { To explore the link } \\
\text { between culture and } \\
\text { dementia with a focus } \\
\text { on the influence of the } \\
\text { belief in dementia as } \\
\text { witchcraft and } \\
\text { people with dementia } \\
\text { are witches }\end{array}$ & $\begin{array}{l}\text { Open, narrative interviews } \\
\text { Purposive sampling } \\
\text { Content-focused } \\
\text { hermeneutic approach }\end{array}$ & $\begin{array}{l}\text { Two themes emerged: } \\
\text {-belief in witchcraft: any person } \\
\text { who behaved strangely or } \\
\text { abnormally would be consider to } \\
\text { be a witch, which would cause }\end{array}$ & $\begin{array}{l}\text { Accusations of witchcraft } \\
\text { continue and within this study } \\
\text { were directed towards vulnerable } \\
\text { older women. An element of } \\
\text { ingrained fear of witchcraft led to } \\
\text { violent acts against these women, } \\
\text { which led some to be cared for in } \\
\text { a nursing home }\end{array}$ \\
\hline
\end{tabular}




\begin{tabular}{|c|c|c|c|c|}
\hline & & $\begin{array}{l}\text { Phenomenological analysis } \\
\text { Family members }(n=1) \\
\text { Nurses working in a care } \\
\text { home }(n=7)\end{array}$ & $\begin{array}{l}\text { people to become fearful of this } \\
\text { person } \\
\text {-need for dementia knowledge and } \\
\text { education: nurses viewed this as a } \\
\text { priority for the general public and } \\
\text { the need for sessions to be } \\
\text { delivered widely including in } \\
\text { churches and schools }\end{array}$ & $\begin{array}{l}\text { Nurses beliefs and perceptions of } \\
\text { dementia as witchcraft only } \\
\text { changed due to working in a } \\
\text { nursing home with people with } \\
\text { dementia } \\
\text { The importance of education for } \\
\text { the general public, and health } \\
\text { care professionals remains } \\
\text { essential }\end{array}$ \\
\hline $\begin{array}{l}\text { Mushi } \\
2014 \\
\text { Tanzania }\end{array}$ & $\begin{array}{l}\text { To explore how the } \\
\text { community describes } \\
\text { dementia and the } \\
\text { experiences of people } \\
\text { with dementia and their } \\
\text { family members, } \\
\text { including social support }\end{array}$ & $\begin{array}{l}\text { Cross-sectional qualitative } \\
\text { study } \\
\text { Purposive sample } \\
\text { Content analysis }\end{array}$ & $\begin{array}{l}\text { Four themes emerged: } \\
\text {-lack of knowledge of dementia, no } \\
\text { participant knew the term } \\
\text { dementia, some participants ( } n=9 \text { ) } \\
\text { believed dementia to be a curse or } \\
\text { witchcraft } \\
\text {-symptoms identified as dementia } \\
\text { included forgetting: things or }\end{array}$ & $\begin{array}{l}\text { The knowledge of dementia in } \\
\text { these participants was } \\
\text { inadequate and was generally } \\
\text { accepted as a problem of old age } \\
\text { and therefore family members } \\
\text { lacked the basic skills to care for a } \\
\text { person with dementia } \\
\text { Education regarding the risk } \\
\text { factors, cause, treatment and } \\
\text { care people with dementia are } \\
\text { urgently required at family level }\end{array}$ \\
\hline
\end{tabular}




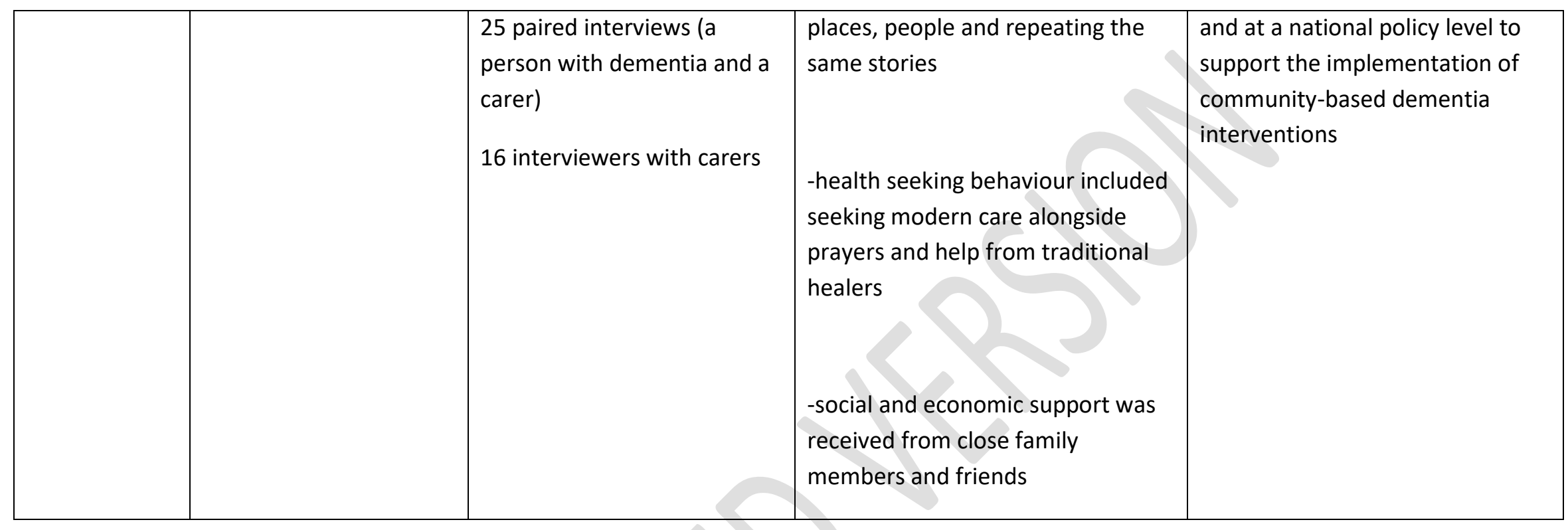

